\title{
Erratum
}

\section{Intelligent Assistive Technology for Alzheimer's Disease and Other Dementias: A Systematic Review}

Marcello Ienca, Fabrice Jotterand, Bernice Elger, Maurizio Caon, Alessandro Scoccia Pappagallo, Reto W. Kressig and Tenzin Wangmo

[Journal of Alzheimer's Disease 56(4), 2017, 1301-1340, DOI: 10.3233/JAD-161037]

http://content.iospress.com/articles/journal-of-alzheimers-disease/jad161037

On page 1301, in the author listing, the author Fabrice Jotterand was incorrectly listed as Jotterand Fabrice (first and last name switched). The author's correct name is F. Jotterand. 